\title{
The thick and thin of the central corneal thickness in glaucoma
}

\author{
Graham W. Belovay ${ }^{1} \cdot$ Ivan Goldberg ${ }^{2,3,4}$
}

Received: 1 November 2017 / Revised: 15 January 2018 / Accepted: 17 January 2018 / Published online: 15 February 2018

(c) The Royal College of Ophthalmologists 2018

\begin{abstract}
Central corneal thickness (CCT) is an important parameter in the assessment of any potential glaucoma patient. While it affects prognosis in ocular hypertension, its value in patients diagnosed with glaucoma is less certain. There are several biological factors and genetic components that may influence glaucoma progression, which have been associated with thinner CCT. The CCT itself can be affected by several factors including ethnicity, age, sex, glaucoma medications, genetics, and the subtype of glaucoma. Besides, there is variability in the measurement of CCT between difference types of devices. These factors need to be considered in the evaluation of glaucoma patients' CCT and its effect on interpretation of intraocular pressure levels and risk stratification.
\end{abstract}

\section{Introduction}

Central cornea thickness (CCT) is an integral component in the workup of any new patient suspected of having glaucoma. It is part of guidelines promulgated, for example, by the American Academy of Ophthalmology, Canadian Ophthalmology Society, Asia-Pacific Glaucoma Society, European Glaucoma Society, and Australian National Health and Medical Research Council. The CCT can be influenced by many factors including: ethnicity, genetics, age, glaucoma treatment and the subtype of glaucoma. The measurement of CCT by the various types of devices are also not interchangeable. All these above factors need to be considered in the evaluation of a glaucoma patient's CCT and its effect on interpretation of intraocular pressure (IOP) levels and risk stratification.

Graham W. Belovay

gbelovay@gmail.com

1 Clarity Eye Institute, Vaughan, Canada

2 Glaucoma Unit, Sydney Eye Hospital, Sydney, Australia

3 Discipline of Ophthalmology, University of Sydney, Sydney, Australia

4 Eye Associates, Sydney, Australia

\section{Methods}

An Ovid MEDLINE search was performed using the following resource: Epub Ahead of Print, In-Process \& Other Non-Indexed Citations, Ovid MEDLINE Daily and Ovid MEDLINE 1946-Present (September 2017). A search using keywords "Central Corneal Thickness" OR "CCT" limited by human studies was performed. The results were filtered by those with a "Glaucoma" subject heading. From these results relevant studies were identified.

\section{Measurement tools}

\section{CCT measurement}

Owing to its general ease of use, repeatability, and modest cost, the most widespread method to measure CCT is ultrasound pachymetry (UP), which requires contact with the eye, necessitating the use of topical anesthetic and a cooperative patient. It may also be a source of infection or potential damage to the corneal epithelium. Specular microscopy (e.g., Topcon SP-3000P, Topcon Corporation, Tokyo, Japan), optical coherence tomography, rotating Scheimpflug camera (e.g., Pentacam, Oculus Inc., Wetzlar, Germany), optical low-coherence reflectometry (e.g., Lenstar, Haag-Streit AG, Koeniz, Switzerland), and slitscanning optical pachymetry (OPT; e.g., Orbscan, Bausch \& Lomb, Rochester, NY, USA) are other imaging techniques that are non-contact. Results from these OPT 
techniques are not interchangeable between devices and differ significantly compared with UP [1-5]; some devices overestimate $[5,6]$, while others underestimate $[4,7]$. The presence of corneal haze and keratoconus may explain some differences in the measurements between devices [8,9]. Even though in some studies the Pentacam, Orbscan, and the Galilei Dual-Scheimpflug (Ziemer Group, Port, Switzerland) were found to correlate with the UP [8-11], the UP and OPT are not considered interchangeable.

\section{Intraocular pressure measurement}

\section{Devices and CCT}

There are many devices available for measuring IOP, most of which can be influenced by variations in CCT. Goldmann Tonometry (GAT), the gold standard for IOP measurement, was developed based on a 500- $\mu \mathrm{m}$-thick cornea [12]. However, with cannulation studies a CCT of $520 \mu \mathrm{m}$ was found to be the most accurate with GAT [13]. There is a positive correlation between CCT and IOP in GAT $[14,15]$. The Dynamic Contour Tonometry (Zeimer Ophthalmic systems AG, Port, Switzerland) in contrast appears to not be affected by differences in the CCT [16, 17]. The Ocular Response Analyzer (Reichert Inc., Depew, NY, USA), which takes into account corneal hysteresis, provides two IOP measures: Corneal Compensated IOP (IOPcc) and Goldmann correlated IOP (IOPg). The IOPg has been correlated with CCT in several studies [18, 19], but also has shown no correlation [20]. There is no association with CCT in IOPcc measurements [18-20]. In the Tonopen (Reichert Inc.), there may be negligible effect of CCT on the IOP readings [21, 22]. Rebound Tonometry (e.g., iCare, Helsinki, Finland) is affected by CCT [23, 24]; however, one study did show that is was affected by cornea hysteresis and cornea resistance rather than CCT [25]. The pneumotonometer can be significantly influenced by CCT [26]. The Diaton tonometer (Tonom GmbH, Munster, Germany) is independent of CCT as it is applied over the eyelid onto the sclera, so is influenced by variations in those structures instead.

\section{Artifact and correction}

On the basis of the cannulation studies of Ehlers et al., a deviation of $100 \mu \mathrm{m}$ from the "ideal" CCT of $520 \mu \mathrm{m}$ introduces an error of $7 \mathrm{mmHg}$ [13]. To account for this deviation, several methods have been devised including linear correction factors [27, 28], nonlinear models [29], and more intricate mathematical models, taking into account the lesser significance of CCT at lower IOP [30]. Unfortunately, these correcting methods introduce other errors into the interpretation of the IOP results. In addition, the adjusted IOP is unlikely to improve tonometry as a screening tool for open angle glaucoma (OAG) in at-risk populations [31] and is not necessary in population-based assessment [32]. Therefore, attempting to "correct" IOP based on CCT does not provide any benefit in the assessment or management in the glaucoma or glaucoma suspect patient.

IOP correction factors are based on structurally normal corneas with no pathology. Thicker edematous cornea will result in artefactually lower GAT readings owing to reduced rigidity. In comparison, a thinner cornea with scaring may have an artefactually higher reading due to increased rigidity. The increased rigidity in the cornea after cornea crosslinking has been postulated to explain the increase in IOP observed in keratoconus patients after 1 year, despite no change in their CCT [33].

\section{Prognostic factors and associations}

\section{Ocular hypertension and glaucoma suspect}

The Ocular Hypertension Study (OHTS) identified a thinner $\mathrm{CCT}$ as an important predictive factor for development of primary open angle glaucoma (POAG) from ocular hypertension (OHTN) [34]. In this study, a patient with a CCT of $555 \mu \mathrm{m}$ or less had a threefold increased risk of developing glaucoma within 5 years compared with someone with a CCT greater than $588 \mu \mathrm{m}$. This study was limited by having only $7 \%$ of patients with CCT less than $526 \mu \mathrm{m}$, while more than $25 \%$ had a CCT greater than $600 \mu \mathrm{m}$. Even though this distribution could overestimate the significance of CCT, CCT is still considered an important risk factor.

The prediction model from OHTS has been supported by data from the European Glaucoma Prevention Study (EGPS). The pooled OTHS-EGPS-predictive model confirmed CCT as a significant predictor for glaucoma, with every $40 \mu \mathrm{m}$ decrease in CCT associated with a twofold increased risk of developing glaucoma over 5 years [35]. There was no evidence that its predictive value could be attributed to any other risk factors and is therefore considered to be independent.

\section{Glaucoma}

In patients with established glaucoma, the predictive role of $\mathrm{CCT}$ is not as well proven in management or long-term prognosis. However, patients with advanced damage are more likely to have a thin CCT [36].

Population-based studies, including groups from West Africa and East Asia, have shown no difference in CCT between glaucomatous and non-glaucomatous eyes [14, 3740]. However, in the Los Angeles Latino Eye Study, those 
with thin CCT had a significantly higher prevalence of POAG than those with normal or thick corneas [32]. There are several studies showing an association of a thinner CCT (range: $522 \pm 35$ to $537.5 \pm 33.0 \mu \mathrm{m}$ ) in normal tension glaucoma (NTG) compared with those with POAG [36], OHTN [36, 40], or normal eyes [41-43]. No association between NTG and a thinner CCT has been reported [44].

Pseudoexfoliation syndrome (PXF) and pseudoexfoliation glaucoma (PXG) patients have been reported to have thinner CCT [36, 41, 45] or similar CCT compared with normal controls [46]. Palko and Sheybani looked at studies examining corneal alterations in PXF or PXG and found no consistent trend of an effect on CCT [47].

Pigment dispersion syndrome (PDS) and CCT have not been well reported and were excluded from the OHTS study. These patients were included in the EGPS, but as such a tiny cohort were excluded from the pooled OHTS-EGPS analysis. Only a few studies have included PDS and there is no significant difference in CCT for this group compared with normal or POAG eyes, limited by the smaller cohort of patients [36, 48].

Confusingly, patients with primary angle closure (PAC) or PAC glaucoma have been reported with thinner CCT compared with controls (range: $509.7 \pm 27.4$ to $525.9 \pm 5.0$ $\mu \mathrm{m})[41,49]$. Kniestedt et al. found no association in their cohort [36].

\section{Biological factors}

Association between the thin CCT and thin lamina has been proposed. A thin lamina might have less rigidity than a thicker one and could be more susceptible to displacement by IOP fluctuations, leading to increased loss of adjacent axons [50]. Lesk et al. found that their surrogate marker for lamina cribrosa (LC) displacement was greater in patients with thinner CCT [51]. In contrast, Nicolela et al. found that IOP changes of $5 \mathrm{mmHg}$ in range did not have a measurable effect on optic disc topography and no association with thin CCT [52]. This finding was supported in a subsequent study by Omodaka et al. [53]. The disparity may be explained by the duration and severity of glaucoma, which could influence the compliance of the lamina in response to IOP changes [54]. Other studies have found no relationship between CCT and the LC [55, 56].

There is no definitive correlation between Heidelberg retina tomography (Heidelberg, Germany) optic disc parameters and CCT. The Singapore Malay Eye Study found that a thinner CCT was associated with smaller rim area and a greater cup to disc area in subjects with POAG [57]. Similarly, the Tajimi study in Japan found a thinner CCT associated with a larger cup volume [58]. However, in other population-based studies there was no significant relationship with any optic disc parameter $[15,59]$. Some hospital- based studies have found CCT associated with optic disc area [60-62], nasal rim area [63], as well as no significant correlation of CCT and disc size [62].

Siegfried et al. found an inverse correlation between $\mathrm{CCT}$ and partial pressure of oxygen in the anterior chamber angle [64]. The theory is that thin CCT may increase trabecular exposure to oxidative damage.

\section{Genetic associations}

The CCT phenotype is a highly heritable trait based on twin studies [65-67]. There is, however, no single genetic determination for CCT [68]. Genome-wide association studies have identified many CCT-associated loci [69-73], but only the FNDC3B genetic locus has been associated with POAG in a meta-analysis [69]. In addition, the combined genetic effect of these loci explain only a small amount of heritability. The meta-analysis found that genes associated with CCT are involved in collagen and extracellular matrix metabolism, collagen fibril organization, and myosin binding.

\section{Ethnic groups}

Measured average CCT varies between the different ethnic groups, with African Americans and Japanese having thinner CCT consistently compared with other groups [36, 41, 74]. Patients with Indian descent were reported with both thinner [75] and similar CCT [76]. The method of measuring CCT does vary between studies with some using UP and others OPT. As mentioned earlier, these are not interchangeable; therefore, comparing between the two is not accurate. Therefore, as there is no comparison group for the Mongolian patients, their OPT thinner CCT finding is harder to compare [77]. Caucasian, Hispanic, Latino, Chinese, Filipino, Korean, Malay, and Iranian populations have thicker CCT compared to those listed above, as is illustrated in Table 1 [36, 40, 41, 76, 78-82]. Overall, ethnicity should be considered when interpreting CCT, given the variations.

In the OHTS and EGPS, Caucasian patients were the most represented race, with the African American group the second most in OHTS. The African American group had a thinner CCT compared with the Caucasian subjects [83]. In patients with African descent, the Barbados Eye Studies showed that decreased CCT is associated with an increased risk of developing POAG over 9 years (odds ratio (OR) 1.41 95\% confidence interval $1.01-1.96$ per $40 \mu \mathrm{m}$ lower) [84].

\section{Systemic}

There is a positive relationship between CCT with both serum glucose and HbA1c levels. In several studies, some population-based, diabetes mellitus (DM) is associated with 


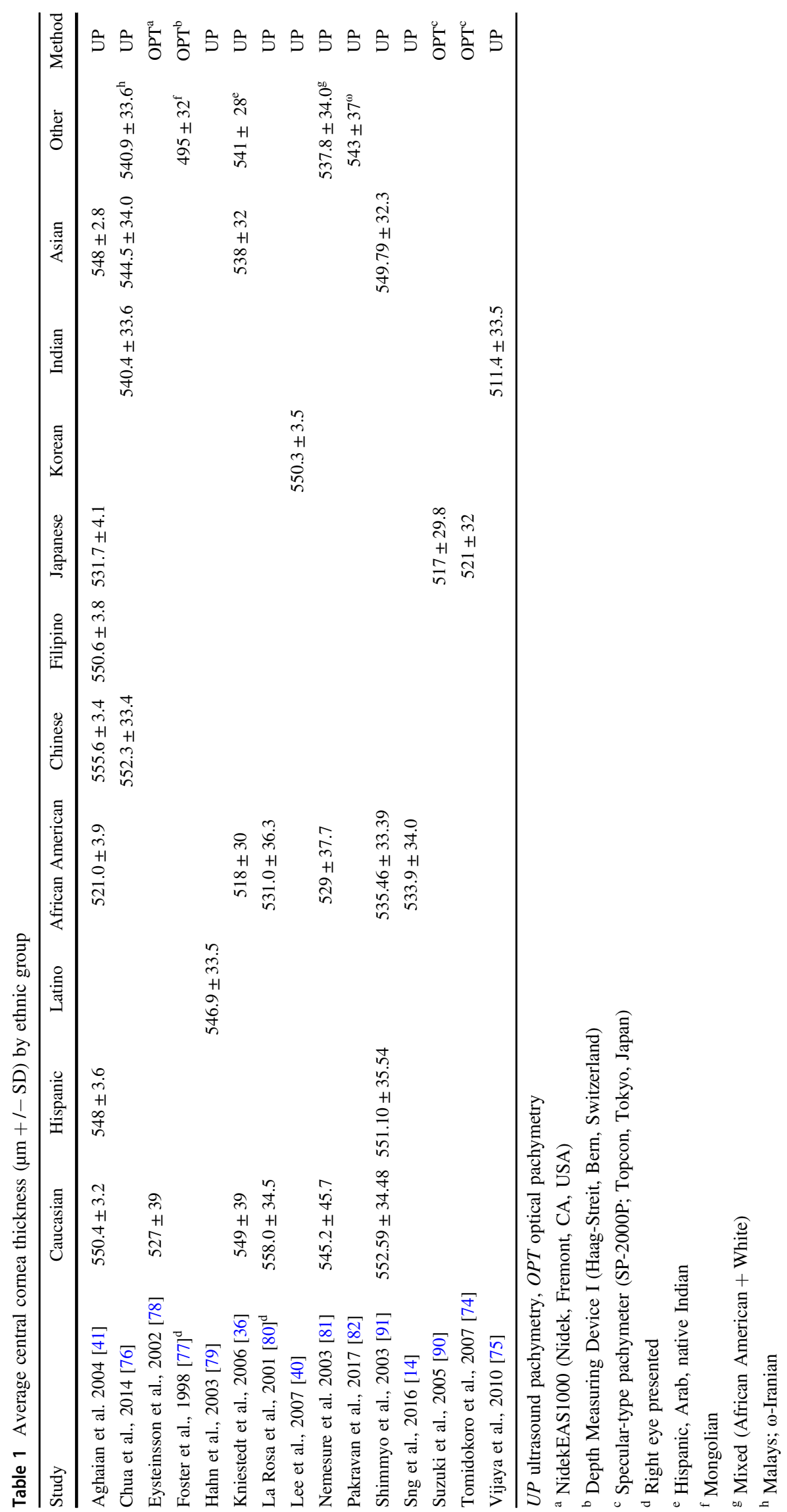


a thicker CCT [59, 81, 85, 86]. However, no association has also been reported [87]. In addition, metabolic syndrome [85] and an increased body mass index [85, 87, 88] are correlated with an increased CCT. Chronic kidney disease that often present in those with DM has also been found to be associated with increased CCT [85]. No association has also been reported [89].

\section{Sex}

The role of sex on CCT is variable as there are reports of no differences between the sexes [40, 41], females having thicker CCT than males [83] and males having thicker CCT than females [14, 39, 79, 87, 90].

\section{Age}

There is a significant inverse correlation between age and CCT, decreasing $\sim 2-10 \mu \mathrm{m}$ per decade [14, 38, 40, 41, 75, $77,79,81,83,90]$. This rate, however, may not be clinical significant. While most studies have agreed on the decrease over time, there are also those that show no significant association of CCT with age [91, 92].

\section{Treatment}

\section{Topical medications}

Topical glaucoma medications are the mainstay of treatment for glaucoma. Depending on the class of medication, they could cause thinning, thickening, or no change to the CCT.

Prostaglandin analogue (PGA) topical drops can decrease, increase, or not affect CCT. The decrease appears to occur most significantly in the first 1-2 years of treatment and mostly in NTG patients (range: $8.6+/-5.2$ to 14.24 $+/-8.18 \mu \mathrm{m}$ ) [93-95]. This appears reversible following cessation [96]. An increase in CCT can also occur as reported in brimatoprost and latanoprost [97]. Iester et al. showed no change to CCT in their Italian Glaucoma Register study [98]. No factor has been identified to explain the difference; however, many of those reporting a decrease have had more NTG patients.

Carbonic anhydrase inhibitor topical drops have been shown to cause irreversible corneal decompensation and increased CCT in eyes with underlying cornea endothelial disease [99]. In healthy corneas there was no effect on the endothelium [100]. In POAG, an increase [101] and no change [98] in CCT both have been reported.

Beta-blocker (BB) topical drops have shown a reversible increase in CCT, with no change to the endothelium [102]. The theory is that cornea homeostasis is interrupted by the inhibition of the endothelium pump-leak mechanism by the medication, resulting in an increase in CCT [103].

Alpha2-Adrenergic topical drops cause a reversible increase over 2 days [104].

\section{Response to treatment}

In OHTN a thicker CCT is associated with a less significant decrease in IOP after starting ocular hypertensive medications [105, 106]. Likewise, glaucoma patients with a thicker CCT have a worse IOP response than those with a thinner CCT [107, 108]. Brandt et al. reported that this reduced response to treatment is more obvious with PGAs than by BB [109]. However, no association was shown between ocular penetration of travoprost and CCT [110]. This study is limited by short-term exposure though; therefore, it cannot report on the effects of chronic use on corneal permeability.

Treatment of OHTN and POAG with selective laser trabeculoplasty (SLT) showed a significantly greater reduction in eyes with thin CCT $(<555 \mu \mathrm{m})$ over a 30-month period [111].

\section{Conclusion}

The CCT of a patient with OHTN, glaucoma suspect, or established glaucoma can be influenced by many different factors: ethnicity, glaucoma treatment, age, and subtype of glaucoma. Thinner CCT is found more often in patients with NTG and angle closure, African American and Japanese patients, those with more advanced glaucoma and is an independent risk factor in OHTN. Its predictive value in established glaucoma is not proven; however, it is important in interpreting IOP results and risk stratification. Despite many proposed mathematical models, correcting GAT IOP does not provide any benefit in the assessment or management of glaucoma. The use of devices that measure IOP independently of CCT would help to overcome its influence; however, they are still not widely incorporated into general clinical practice. The association of CCT with biological factors and genetics in glaucoma will hopefully become clearer as the research expands in these areas.

\section{Compliance with ethical standards}

Conflict of interest The authors declare that they have no competing interests.

\section{References}

1. Bao F, Wang Q, Cheng S, Savini G, Lu W, Feng Y, et al. Comparison and evaluation of central corneal thickness using 2 
new noncontact specular microscopes and conventional pachymetry devices. Cornea. 2014;33:576-81.

2. Borrego-Sanz L, Saenz-Frances F, Bermudez-Vallecilla M, Morales-Fernandez L, Martinez-de-la-Casa JM, Santos-Bueso E, et al. Agreement between central corneal thickness measured using pentacam, ultrasound pachymetry, specular microscopy and optic biometer lenstar is 900 and the influence of Intraocular pressure. Ophthalmologica. 2014;231:226-35.

3. Nam SM, Im CY, Lee HK, Kim EK, Kim T-i, Seo KY. Accuracy of RTVue optical coherence tomography, pentacam, and ultrasonic pachymetry for the measurement of central corneal thickness. Ophthalmology. 2010;117:2096-103.

4. Garcia-Medina JJ, Garcia-Medina M, Garcia-Maturana C, Zanon-Moreno V, Pons-Vazquez S, Pinazo-Duran MD. Comparative study of central corneal thickness using fourier-domain optical coherence tomography versus ultrasound pachymetry in primary open-angle glaucoma. Cornea. 2013;32:9-13.

5. Ang M, Chong W, Huang H, Tay WT, Wong TY, He M-G, et al. Comparison of anterior segment optical tomography parameters measured using a semi-automatic software to standard clinical instruments. PLoS ONE. 2013;8:e65559.

6. Ou T-H, Lai I-C, Teng M-C. Comparison of central corneal thickness measurements by ultrasonic pachymetry, Orbscan II, and SP3000P in eyes with glaucoma or glaucoma suspect. Chang Gung Med J. 2012;35:255-62.

7. Lackner B, Schmidinger G, Pieh S, Funovics MA, Skorpik C. Repeatability and reproducibility of central corneal thickness measurement with Pentacam, Orbscan, and ultrasound. Optom Vis Sci. 2005;82:892-9.

8. Ucakhan OO, Ozkan M, Kanpolat A. Corneal thickness measurements in normal and keratoconic eyes: pentacam comprehensive eye scanner versus noncontact specular microscopy and ultrasound pachymetry. J Cataract Refract Surg. 2006;32: 970-7.

9. Fakhry MA, Artola A, Belda JI, Ayala MJ, Alio JL. Comparison of corneal pachymetry using ultrasound and Orbscan II. J Cataract Refract Surg. 2002;28:248-52.

10. Barkana Y, Gerber Y, Elbaz U, Schwartz S, Ken-Dror G, Avni I, et al. Central corneal thickness measurement with the Pentacam Scheimpflug system, optical low-coherence reflectometry pachymeter, and ultrasound pachymetry. J Cataract Refract Surg. 2005;31:1729-35.

11. Yeter V, Sonmez B, Beden U. Comparison of central corneal thickness measurements by galilei dual-scheimpflug analyzer (r) and ultrasound pachymeter in myopic eyes. Ophthalmic Surg Lasers Imaging. 2012;43:128-34.

12. Goldmann H, Schmidt T. Applanation tonometry. Ophthalmologica. 1957;134:221-42.

13. Ehlers N, Bramsen T, Sperling S. Applanation tonometry and central corneal thickness. Acta Ophthalmol. 1975;53:34-43.

14. Sng C, Barton K, Kim H, Yuan S, Budenz DL. Central corneal thickness and its associations with ocular and systemic factors in an urban West African population. Am J Ophthalmol. 2016;169:268-75.

15. Carbonaro F, Hysi PG, Fahy SJ, Nag A, Hammond CJ. Optic disc planimetry, corneal hysteresis, central corneal thickness, and intraocular pressure as risk factors for glaucoma. Am J Ophthalmol. 2014;157:441-6.

16. Kaufmann C, Bachmann LM, Thiel MA. Comparison of dynamic contour tonometry with Goldmann applanation tonometry. Invest Ophthalmol Vis Sci. 2004;45:3118-21.

17. Kniestedt C, Nee M, Stamper RL. Dynamic contour tonometrya comparative study on human cadaver eyes. Arch Ophthalmol. 2004;122:1287-93.

18. Medeiros FA, Weinreb RN. Evaluation of the influence of corneal biomechanical properties on intraocular pressure measurements using the ocular response analyzer. J Glaucoma. 2006;15:364-70.

19. Bayoumi NH, Bessa AS, El Massry AA. Ocular response analyzer and goldmann applanation tonometry: a comparative study of findings. J Glaucoma. 2010;19:627-31.

20. Oncel B, Dinc U, Orge F, Yalvac B. Comparison of IOP measurement by ocular response analyzer, dynamic contour, Goldmann applanation, and noncontact tonometry. Eur J Ophthalmol. 2009;19:936-41.

21. Bhan A, Browning AC, Shah S, Hamilton R, Dave D, Dua HS. Effect of corneal thickness on intraocular pressure measurements with the pneumotonometer, Goldmann applanation tonometer, and Tono-Pen. Invest Ophthalmol Vis Sci. 2002;43:1389-92.

22. Dohadwala AA, Munger R, Damji KF. Positive correlation between Tono-Pen intraocular pressure and central corneal thickness. Ophthalmology. 1998;105:1849-54.

23. Nakamura M, Darhad U, Tatsumi Y, Fujioka M, Kusuhara A, Maeda $\mathrm{H}$, et al. Agreement of rebound tonometer in measuring intraocular pressure with three types of applanation tonometers. Am J Ophthalmol. 2006;142:332-4.

24. Sahin A, Niyaz L, Yildirim N. Comparison of the rebound tonometer with the Goldmann applanation tonometer in glaucoma patients. Clin Exp Ophthalmol. 2007;35:335-9.

25. Chui WS, Lam A, Chen D, Chiu R. The influence of corneal properties on rebound tonometry. Ophthalmology. 2008;115:80-84.

26. Morgan AJ, Harper J, Hosking SL, Gilmartin B. The effect of corneal thickness and corneal curvature on pneumatonometer measurements. Curr Eye Res. 2002;25:107-12.

27. Bao F, Huang Z, Huang J, Wang J, Deng M, Li L, et al. Clinical evaluation of methods to correct intraocular pressure measurements by the goldmann applanation tonometer, ocular response analyzer, and corvis ST tonometer for the effects of corneal stiffness parameters. J Glaucoma. 2016;25:510-9.

28. Orssengo GJ, Pye DC. Determination of the true intraocular pressure and modulus of elasticity of the human cornea in vivo. Bull Math Biol. 1999;61:551-72.

29. Liu J, Roberts CJ. Influence of corneal biomechanical properties on intraocular pressure measurement-quantitative analysis. J Cataract Refract Surg. 2005;31:146-55.

30. Elsheikh A, Wang D, Kotecha A, Brown M, Garway-Heath D. Evaluation of goldmann applanation tonometry using a nonlinear finite element ocular model. Ann Biomed Eng. 2006;34:1628-40.

31. de Saint Sardos A, Fansi K, Chagnon M, Harasymowycz PJ. Intraocular pressure adjusted for central corneal thickness as a screening tool for open-angle glaucoma in an at-risk population. Can J Opthalmol. 2009;44:571-5.

32. Francis BA, Varma R, Chopra V, Lai M-Y, Shtir C, Azen SP, et al. Intraocular pressure, central corneal thickness, and prevalence of open-angle glaucoma: the Los Angeles Latino Eye Study. Am J Ophthalmol. 2008;146:741-6.

33. Kasumovic SS, Mavija M, Kasumovic A, Lepara O, Duric-Colic $\mathrm{B}, \mathrm{Cabric} \mathrm{E}$, et al. Intraocular pressure measurements referring to the corneal thickness in keratoconic eyes after corneal crosslinking with riboflavin and ultraviolet A. Med Arch. 2015;69:334-8.

34. Gordon MO, Beiser JA, Brandt JD, Heuer DK, Higginbotham EJ, Johnson CA, et al. The Ocular Hypertension Treatment Study -Baseline factors that predict the onset of primary open-angle glaucoma. Arch Ophthalmol. 2002;120:714-20.

35. Gordon MO. Ocular Hypertension Treatment S, European Prevention Study G. Validated prediction model for the development of primary open-angle glaucoma in individuals with ocular hypertension. Ophthalmology. 2007;114:10-9. 
36. Kniestedt C, Lin S, Choe J, Nee M, Bostrom A, Sturmer J, et al. Correlation between intraocular pressure, central corneal thickness, stage of glaucoma, and demographic patient data: prospective analysis of biophysical parameters in tertiary glaucoma practice populations. J Glaucoma. 2006;15:91-7.

37. Day AC, Machin D, Aung T, Gazzard G, Husain R, Chew PTK, et al. Central corneal thickness and glaucoma in East Asian people. Invest Ophthalmol Vis Sci. 2011;52:8407-12.

38. Wang D, Huang W, Li Y, Zheng Y, Foster PJ, Congdon N, et al. Intraocular pressure, central corneal thickness, and glaucoma in Chinese adults: the Liwan Eye Study. Am J Ophthalmol. 2011;152:454-62.

39. Xu L, Zhang H, Wang YX, Jonas JB. Central corneal thickness and glaucoma in adult Chinese The Beijing Eye Study. J Glaucoma. 2008;17:647-53.

40. Lee ES, Kim CY, Ha SJ, Seong GJ, Hong YJ. Central corneal thickness of Korean patients with glaucoma. Ophthalmology. 2007;114:927-30.

41. Aghaian E, Choe JE, Lin S, Stamper RL. Central corneal thickness of Caucasians, Chinese, Hispanics, Filipinos, African Americans, and Japanese in a glaucoma clinic. Ophthalmology. 2004;111:2211-9.

42. Shah S, Chatterjee A, Mathai M, Kelly SP, Kwartz J, Henson D, et al. Relationship between corneal thickness and measured intraocular pressure in a general ophthalmology clinic. Ophthalmology. 1999;106:2154-60.

43. Shin J, Lee J-W, Kim E-A, Caprioli J. The effect of corneal biomechanical properties on rebound tonometer in patients with normal-tension glaucoma. Am J Ophthalmol. 2015;159:144-54.

44. Grise-Dulac A, Saad A, Abitbol O, Febbraro J-L, Azan E, Moulin-Tyrode C, et al. Assessment of corneal biomechanical properties in normal tension glaucoma and comparison with open-angle glaucoma, ocular hypertension, and normal eyes. J Glaucoma. 2012;21:486-9.

45. Ozcura F, Aydin S, Dayanir V. Central corneal thickness and corneal curvature in pseudoexfoliation syndrome with and without glaucoma. J Glaucoma. 2011;20:410-3.

46. Kocabeyoglu S, Mocan MC, Irkec M, Karakaya J. In vivo confocal microscopic evaluation of corneas in patients with exfoliation syndrome. J Glaucoma. 2016;25:193-7.

47. Palko JR, Qi O, Sheybani A. Corneal alterations associated with pseudoexfoliation syndrome and glaucoma: a literature review. J Ophthalmic Vis Res. 2017;12:312-24.

48. Murrell WJ, Shihab Z, Lamberts DW, Avera B. The corneal endothelium and central corneal thickness in pigmentary dispersion syndrome. Arch Ophthalmol. 1986;104:845-6.

49. Tan H-K, Ahmad Tajuddin L-S, Lee M-Y, Ismail S, Wan-Hitam W-H. A study on the central corneal thickness of primary angle closure and primary angle closure glaucoma and its effect on visual field progression. Asia-Pac J Ophthalmol (Phila, Pa). 2015;4:161-5.

50. Burgoyne CF, Morrison JC. The anatomy and pathophysiology of the optic nerve head in glaucoma. J Glaucoma. 2001;10 (5Suppl 1):S16-18.

51. Lesk MR, Hafez AS, Descovich D. Relationship between central corneal thickness and changes of optic nerve head topography and blood flow after intraocular pressure reduction in open-angle glaucoma and ocular hypertension. Arch Ophthalmol. 2006;124:1568-72.

52. Nicolela MT, Soares AS, Carrillo MM, Chauhan BC, LeBlanc $\mathrm{RP}$, Artes PH. Effect of moderate intraocular pressure changes on topographic measurements with confocal scanning laser tomography in patients with glaucoma. Arch Ophthalmol. 2006;124:633-40.

53. Omodaka K, Takahashi S, Matsumoto A, Maekawa S, Kikawa $\mathrm{T}$, Himori $\mathrm{N}$, et al. Clinical factors associated with lamina cribrosa thickness in patients with glaucoma, as measured with swept source optical coherence tomography. PLoS ONE. 2016;11:4.

54. Quigley H, Arora K, Idrees S, Solano F, Bedrood S, Lee C, et al. Biomechanical responses of lamina cribrosa to intraocular pressure change assessed by optical coherence tomography in glaucoma eyes. Invest Ophthalmol Vis Sci. 2017;58:2566-77.

55. Jonas JB, Holbach L. Central corneal thickness and thickness of the lamina cribrosa in human eyes. Invest Ophthalmol Vis Sci. 2005;46:1275-9.

56. Ren R, Li B, Gao F, Li L, Xu X, Wang N, et al. Central corneal thickness, lamina cribrosa and peripapillary scleral histomorphometry in non-glaucomatous Chinese eyes. Graefes Arch Clin Exp Ophthalmol. 2010;248:1579-85.

57. Wu RY, Zheng YF, Wong TY, Cheung CY, Loon SC, Chauhan $\mathrm{BC}$, et al. Relationship of central corneal thickness with optic disc parameters: the Singapore Malay Eye Study. Invest Ophthalmol Vis Sci. 2011;52:1320-4.

58. Abe H, Shirakashi M, Tsutsumi T, Araie M, Tomidokoro A, Iwase A, et al. Laser scanning tomography of optic discs of the normal Japanese population in a population-based setting. Ophthalmology. 2009;116:223-30.

59. Hawker MJ, Edmunds MR, Vernon SA, Hillman JG, MacNab HK. The relationship between central corneal thickness and the optic disc in an elderly population: the Bridlington Eye Assessment Project. Eye. 2009;23:56-62.

60. Saenz-Frances F, Janez L, Borrego-Sanz L, Berrozpe-Villabona C, Maria Martinez-de-la-Casa J, Morales-Fernandez L, et al. Correlations between corneal and optic nerve head variables in healthy subjects and patients with primary open angle glaucoma. Int J Ophthalmol. 2015;8:1156-61.

61. Pakravan M, Parsa A, Sanagou M, Parsa CF. Central corneal thickness and correlation to optic disc size: a potential link for susceptibility to glaucoma. Br J Ophthalmol. 2007;91:26-8.

62. Terai N, Spoerl E, Pillunat LE, Kuhlisch E, Schmidt E, Boehm AG. The relationship between central corneal thickness and optic disc size in patients with primary open-angle glaucoma in a hospital-based population. Acta Ophthalmol. 2011;89: 556-9.

63. Kourkoutas D, Georgopoulos G, Maragos A, Apostolakis I, Tsekouras G, Karanasiou IS, et al. New nonlinear multivariable model shows the relationship between central corneal thickness and HRTII topographic parameters in glaucoma patients. Clin Ophthalmol. 2009;3:313-23.

64. Siegfried CJ, Shui Y-B, Bai F, Beebe DC. Central corneal thickness correlates with oxygen levels in the human anterior chamber angle. Am J Ophthalmol. 2015;159:457-62.

65. Toh TY, Liew SHM, MacKinnon JR, Hewitt AW, Poulsen JL, Spector TD, et al. Central corneal thickness is highly heritable: the twin eye studies. Invest Ophthalmol Vis Sci. 2005;46:3718-22.

66. Toth GZ, Racz A, Tarnoki AD, Tarnoki DL, Szekelyhidi Z, Littvay L, et al. Genetic covariance between central corneal thickness and anterior chamber volume: a Hungarian twin study. Twin Res Human Genet. 2014;17:397-404.

67. Zheng Y, Ge J, Huang G, Zhang J, Liu B, Hur Y-M, et al. Heritability of central corneal thickness in Chinese: the Guangzhou twin eye study. Invest Ophthalmol Vis Sci. 2008;49:4303-7.

68. Rahman ML, Bunce C, Healey PR, Mitchell P, Sham PC, McGuffin $\mathrm{P}$, et al. Commingling analyses of central corneal thickness and adjusted intraocular pressure in an older Australian population. Invest Ophthalmol Vis Sci. 2010;51:2512-8.

69. Lu Y, Vitart V, Burdon KP, Khor CC, Bykhovskaya Y, Mirshahi $\mathrm{A}$, et al. Genome-wide association analyses identify multiple loci 
associated with central corneal thickness and keratoconus. Nat Genet. 2013;45:155-63.

70. Cornes BK, Khor CC, Nongpiur ME, Xu L, Tay W-T, Zheng Y, et al. Identification of four novel variants that influence central corneal thickness in multi-ethnic Asian populations. Human Mol Genet. 2012;21:437-45.

71. Lu Y, Dimasi DP, Hysi PG, Hewitt AW, Burdon KP, Toh T, et al. Common genetic variants near the Brittle Cornea Syndrome locus ZNF469 influence the blinding disease risk factor central corneal thickness. PLoS Genet. 2010;6:e1000947.

72. Vitart V, Bencic G, Hayward C, Skunca Herman J, Huffman J, Campbell S, et al. New loci associated with central cornea thickness include COL5A1, AKAP13 and AVGR8. Human Mol Genet. 2010;19:4304-11.

73. Vithana EN, Aung T, Khor CC, Cornes BK, Tay WT, Sim X, et al. Collagen-related genes influence the glaucoma risk factor, central corneal thickness. Hum Mol Genet. 2011;20:649-58.

74. Tomidokoro A, Araie M, Iwase A. Corneal thickness and relating factors in a popu lation-based study in Japan: the tajimi study. Am J Ophthalmol. 2007;144:152-4.

75. Vijaya L, George R, Arvind H, Ramesh SV, Baskaran M, Raju $\mathrm{P}$, et al. Central corneal thickness in Adult South Indians: the Chennai Glaucoma Study. Ophthalmology. 2010;117:700-4.

76. Chua J, Tham YC, Liao J, Zheng Y, Aung T, Wong TY, et al. Ethnic differences of intraocular pressure and central corneal thickness: the Singapore Epidemiology of Eye Diseases Study. Ophthalmology. 2014;121:2013-22.

77. Foster PJ, Baasanhu J, Alsbirk PH, Munkhbayar D, Uranchimeg D, Johnson GJ. Central corneal thickness and intraocular pressure in a Mongolian population. Ophthalmology. 1998;105:969-73.

78. Eysteinsson T, Jonasson F, Sasaki H, Arnarsson A, Sverrisson T, Sasaki K, et al. Central corneal thickness, radius of the corneal curvature and intraocular pressure in normal subjects using noncontact techniques: Reykjavik Eye Study. Acta Ophthalmol Scand. 2002;80:11-15.

79. Hahn S, Azen S, Ying-Lai M, Varma R, Los Angeles Latino Eye Study G. Central corneal thickness in Latinos. Invest Ophthalmol Vis Sci. 2003;44:1508-12.

80. La Rosa FA, Gross RL, Orengo-Nania S. Central corneal thickness of Caucasians and African Americans in glaucomatous and nonglaucomatous populations. Arch Ophthalmol. 2001;119:23-27.

81. Nemesure B, Wu SY, Hennis A, Leske MC, Barbados Eye Study G. Corneal thickness and intraocular pressure in the Barbados Eye Studies. Arch Ophthalmol. 2003;121:240-4.

82. Pakravan M, Javadi MA, Yazdani S, Ghahari E, Behroozi Z, Soleimanizad R, et al. Distribution of intraocular pressure, central corneal thickness and vertical cup-to-disc ratio in a healthy Iranian population: the Yazd Eye Study. Acta Ophthalmol. 2017;95:e144-51.

83. Brandt JD, Beiser JA, Kass MA, Gordon MO. Central corneal thickness in the Ocular Hypertension Treatment Study (OHTS). Ophthalmology. 2001;108:1779-88.

84. Leske MC, Wu S-Y, Hennis A, Honkanen R, Nemesure B, Grp BES. Risk factors for incident open-angle glaucoma. Ophthalmology. 2008;115:85-93.

85. Su DHW, Wong TY, Foster PJ, Tay W-T, Saw S-M, Aung T. Central corneal thickness and its associations with ocular and systemic factors: the Singapore Malay Eye Study. Am J Ophthalmol. 2009;147:709. e701

86. Su DH, Wong TY, Wong WL, Saw SM, Tan DT, Shen SY, et al. Diabetes, hyperglycemia, and central corneal thickness: the Singapore Malay Eye Study. Ophthalmology. 2008;115:964-8. e961
87. Elflein HM, Pfeiffer N, Hoffmann EM, Hoehn R, Kottler U, Lorenz K, et al. Correlations between central corneal thickness and general anthropometric characteristics and cardiovascular parameters in a large European cohort from the Gutenberg Health Study. Cornea. 2014;33:359-65.

88. Nangia V, Jonas JB, Sinha A, Matin A, Kulkarni M. Central corneal thickness and its association with ocular and general parameters in Indians: the Central India Eye and Medical Study. Ophthalmology. 2010;117:705-10.

89. Nongpiur ME, Wong TY, Sabanayagam C, Lim SC, Tai ES, Aung T. Chronic kidney disease and intraocular pressure: the Singapore Malay Eye Study. Ophthalmology. 2010;117:477-83.

90. Suzuki S, Suzuki Y, Iwase A, Araie M. Corneal thickness in an ophthalmologically normal Japanese population. Ophthalmology. 2005;112:1327-36.

91. Shimmyo M, Ross AJ, Moy A, Mostafavi R. Intraocular pressure, Goldmann applanation tension, corneal thickness, and corneal curvature in Caucasians, Asians, Hispanics, and African Americans. Am J Ophthalmol. 2003;136:603-13.

92. Wolfs RC, Klaver CC, Vingerling JR, Grobbee DE, Hofman A, de Jong PT. Distribution of central corneal thickness and its association with intraocular pressure: the Rotterdam Study. Am J Ophthalmol. 1997;123:767-72.

93. Panos GD, Konstantinidis A, Mendrinos E, Kozobolis V, Perente I, Gatzioufas Z. Effect of Tafluprost $0.0015 \%$ on central corneal thickness in patients with primary open-angle glaucoma. Curr Eye Res. 2013;38:977-82.

94. Lee H, Cho BJ. Long-term effect of latanoprost on central corneal thickness in normal-tension glaucoma: five-year follow-up results. J Ocul Pharmacol Ther. 2015;31:152-5.

95. Zhong Y, Shen X, Yu J, Tan H, Cheng Y. The comparison of the effects of latanoprost, travoprost, and bimatoprost on central corneal thickness. Cornea. 2011;30:861-4.

96. Meda R, Wang Q, Paoloni D, Harasymowycz P, Brunette I. The impact of chronic use of prostaglandin analogues on the biomechanical properties of the cornea in patients with primary open-angle glaucoma. Br J Ophthalmol. 2017;101:120-5.

97. Bafa M, Georgopoulos G, Mihas C, Stavrakas P, Papaconstantinou D, Vergados I. The effect of prostaglandin analogues on central corneal thickness of patients with chronic open-angle glaucoma: a 2-year study on 129 eyes. Acta Ophthalmol. 2011;89:448-51.

98. Iester M, Telani S, Brusini P, Rolle T, Fogagnolo P, Martini E, et al. Central corneal thickness and glaucoma treatment: an Italian multicenter cross-sectional study. J Ocul Pharmacol Ther. 2013;29:469-73.

99. Konowal A, Morrison JC, Brown SVL, Cooke DL, Maguire LJ, Verdier DV, et al. Irreversible corneal decompensation in patients treated with topical dorzolamide. Am J Ophthalmol. 1999;127:403-6.

100. Lass JH, Khosrof SA, Laurence JK, Horwitz B, Ghosh K, Adamsons I. A double-masked, randomized, 1-year study comparing the corneal effects of dorzolamide, timolol, and betaxolol. Dorzolamide Corneal Effects Study Group. Arch Ophthalmol. 1998;116:1003-10.

101. Wilkerson M, Cyrlin M, Lippa EA, Esposito D, Deasy D, Panebianco D, et al. Four-week safety and efficacy study of dorzolamide, a novel, active topical carbonic anhydrase inhibitor. Arch Ophthalmol. 1993;111:1343-50.

102. Grueb M, Rohrbach JM. Effect of timolol on central corneal thickness. Eur J Ophthalmol. 2013;23:784-8.

103. Nielsen CB, Nielsen PJ. Effect of alpha- and beta-receptor active drugs on corneal thickness. Acta Ophthalmol. 1985;63:351-4.

104. Grueb M, Mielke J, Rohrbach JM, Schlote T. Effect of brimonidine on corneal thickness. J Ocul Pharmacol Ther. 2011;27:503-9. 
105. Kass MA, Heuer DK, Higginbotham EJ, Johnson CA, Keltner JL, Miller JP, et al. The Ocular Hypertension Treatment Studya randomized trial determines that topical ocular hypotensive medication delays or prevents the onset of primary open-angle glaucoma. Arch Ophthalmol. 2002;120:701-13.

106. Johnson TV, Toris CB, Fan S, Camras CB. Effects of central corneal thickness on the efficacy of topical ocular hypotensive medications. J Glaucoma. 2008;17:89-99.

107. Harasymowycz PJ, Papamatheakis DG, Ennis M, Brady M, Gordon KD. Travoprost Central Corneal Thickness Study G. Relationship between travoprost and central corneal thickness in ocular hypertension and open-angle glaucoma. Cornea. 2007;26:34-41.

108. Birt CM, Buys YM, Kiss A, Trope GE. Toronto Area Glaucoma $\mathrm{S}$. The influence of central corneal thickness on response to topical prostaglandin analogue therapy. Can J Ophthalmol. 2012;47:51-4.
109. Brandt JD, Beiser JA, Gordon MO, Kass MA. Ocular Hypertension Treatment Study G. Central corneal thickness and measured IOP response to topical ocular hypotensive medication in the Ocular Hypertension Treatment Study. Am J Ophthalmol. 2004;138:717-22.

110. Martinez-de-la-Casa JM, Rayward O, Saenz-Frances F, SantosBueso E, Mendez-Hernandez C, Herrero-Vanrell R, et al. Effects of corneal thickness on the intraocular penetration of travoprost 0.004\%. Eye. 2012;26:972-5.

111. Shazly TA, Latina MA, Dagianis JJ, Chitturi S. Effect of central corneal thickness on the long-term outcome of selective laser trabeculoplasty as primary treatment for ocular hypertension and primary open-angle glaucoma. Cornea. 2012;31:883-6. 